\title{
The Effect of Mindfulness Meditation on Academic Performance of Students
}

\author{
Yang $\mathrm{Liu}^{1, *}{ }^{*}$, Yuqing $\mathrm{Liu}^{2, \dagger}$, Chaoyu Wang ${ }^{3, \dagger}$ \\ ${ }^{1}$ School of Arts Monash University, Melbourne, 3800, Australia \\ ${ }^{2}$ School of Journalism and Communication Wuhan University, Wuhan, 430072, China \\ ${ }^{3}$ College of Arts and Science University of Saskatchewan, S7N 5A2, Saskatoon, Canada \\ These authors contributed equally. \\ *Corresponding author. Email: yliu0173@student.monash.edu
}

\begin{abstract}
School settings had been full of stressors that negatively influence students' mental health and academic performance. For solving students' academic performance issues, mindfulness mediation had been used to improve their academic outcomes. This study had applied the information process theory to demonstrate the internal mechanism between mindfulness mediation and academic performance in three pathways with three major sections: cognitive process (students' academic performance could be enhanced by improving attention on learning), information storage (by improving their working memory through mindfulness meditation), and executive cognition (by improving students' overall executive function). This study had benefited from the summary of the mechanism of mindfulness meditation and academic performance, promoting the development of mindfulness meditation-related activities and applications, and improving students' participation in mindfulness meditation interventions, thereby improving their academic performance.
\end{abstract}

Keywords: meditation, academic performance, attention, memory, executive function

\section{INTRODUCTION}

High levels of stress have been generally perceived by students, which have partly been attributed to interpersonal interaction pressure, life pressure, poverty, violence, especially academic pressure in school settings [1]. Incorporating schooling into one's daily life might be another source of stress, impairing academic performance and quality of life [2]. Moreover, students' well-being has become a worldwide concern because they have been at risk of anxiety, loneliness, and stress [3]. Therefore, the above pressure perceived by students has significant negative impacts on students' mental health, even leading to psychological disorders and poor academic performance [1]. Mindfulness mediation has been applied to improve well-being and mental health to improve students' health status and academic performance. Mindfulness meditation, a clinically proven method, involves nonjudgmentally concentrating people's attention on the current moment [4]. It can enhance people's attention, memory, and critical awareness, promoting students' social skills and academic outcomes [5].
Mindfulness refers to "paying attention in a particular way: on purpose, in the present moment, and nonjudgmentally" [6]. Mindfulness meditation (MM) practice, which uses meditation to achieve mindfulness, allows people to recall and reconstruct their experiences by connecting their minds with the present moment and increasing awareness of their surroundings and inner thoughts [7]. The first mindfulness-based intervention (MBI) for psychotherapy is mindfulness-based stress reduction (MBSR) [8] which brought together mindfulness practice (e.g., walking, eating) and yoga into an eight-week intensive course of group sessions and homework tasks. Based on the MBSR, mindfulnessbased cognitive therapy (MBCT) [9] was developed to alleviate depression, incorporating mindfulness practices such as meditation and breathing exercises into eightweek sessions. MM is beneficial for improving attention $[4,10]$, memory [11] and executive function [12].

It is proved that $\mathrm{MM}$ is positively related to academic performance, such as using breathing techniques, sitting meditation and MBI. Improving academic performance (AP) can be reflected in test scores and learning abilities or skills. Campbell (2021) found that mindfulness 
exercises improved test scores in reading and mathematics for third- to fifth-graders [13]. A study has shown that meditation training positively impacts philosophy, Spanish and history, and foreign language learning [14]. MM has also been demonstrated to help with reading comprehension on the GRE [15]. The positive effect of MM on AP is mainly through cognitive mechanisms. By improving self-regulation and resilience, students' social and emotional well-being is guaranteed, thereby enhancing the academic performance of children [13]. One study has shown that mindfulness training improves concentration and reduces distractions under challenging tasks [15].

Information processing theory (IPT) is the study of How people perceive, transform, reduce, interpret, store, retrieve and use information [16]. Information processing theory considers information as the basic means of learning and explains learning from the perspective of a memory system [16].

Most of the previous studies directly conducted experiments to prove the influence of MM on AP and measured and found possible mediating variables through scales and other tools. Several important mediating variables here, such as attention and memory, also play a significant role in the theoretical model of information processing. In the past decades, the development of information processing models has helped cognitive psychologists gain a better understanding of how humans think, reason and learn [17]. Now using the perspective of information processing theory to explore the influence of MM on AP. On the one hand, it can explain the process and mechanism of influence more deeply, and on the other hand, it can also organically correlate the intermediary variables in previous empirical studies. The information processing model consists of three main elements [18]: (1) Information storage, (2) Cognitive process, (3) Executive cognition.

Information storage is where information is stored. Information storage can be divided into three different types of memory components: sensory or memory, shortterm memory (processor), and long-term memory [16]. This section focused on short-term memory, as well as another concept related to short-term memory, working memory (WM). In the context of the IPT model, the cognitive process is a mental activity in which information is transferred from one kind of memory to another, emphasizing this activity process [18]. This process involves attention, perception, repetition and other factors. In the cognitive process, information learned is selected by attention, converted into meaningful information by perception, and transferred from processor memory to long-term memory by repetition [17][18]. Schunk (2016) emphasizes initiative in the learning process, which means this process is complex and highly dynamic [19], and this complexity is mainly due to executive cognition [17]. Executive cognition (EC) is the individual's cognition of their own way of thinking and learning behaviour; that is, individuals can recognize the advantages and disadvantages of their own cognition in the learning process [16]. Executive cognition is a high-level cognitive process generally considered to be planning, judgment and self-monitoring capabilities [20]. Executive function (EF) is also a high-level cognitive process, including the concepts of planning, decisionmaking, emotional self-regulation and psychological flexibility [21]. By definition and content, EF and EC can be used interchangeably in this context [21].

Although many empirical studies have demonstrated a relationship between mindfulness meditation and academic performance, the studies have been fragmented without a review to connect them. Therefore, this study will summarize the mechanisms between mindfulness mediation and academic performance in three sections: attention, memory, metacognitive ability, applying the information process theory's three components: cognitive process, information storage and executive cognition.

\section{THE MECHANISM OF MINDFULNESS MEDITATION}

\subsection{Cognitive Process-Attention}

Attention is considered a fundamental pillar on which all learning depends; for instance, listening lessons significantly impact students' immediate reactions and help their attentional focus on critical knowledge [22]. Attention is defined as a cognitive mechanism of the brain that enables people to process relevant input thoughts or actions while ignoring irrelevant or distracting activities [22], such as bad moods and anxiety. The attention process includes selective arousal, filtering, discarding, and suppressing the required information for specific stimuli [23].

Many studies applied MM for students by a set of breath training [4][24]. This training helped students develop a sense of calm after recording their thoughts and feelings, thereby increasing awareness and WM [4]. In addition, studies demonstrated that MM training could reduce the student's tendency to pay attention to painful thoughts and contemplations, such as internal attention to negative self-evaluation and self-deprecation, which may decrease students' AP [24]. Moreover, MM decreases anxiety, reducing students' social skills and AP [4]. Furthermore, the regulation of attention allows students to maintain awareness for more extended periods of time and be less impressionable to distractions, improving learning and test scores [10].

Attentional control theory is predicted to explain the internal mechanism between attention and students' 
academic outcomes. Attention control theory proposes that anxiety can damage the goal-driven attention system and interfere with the transfer and inhibition functions of the central executive system, which has a more significant negative impact on processing efficiency than on operational performance [25]. Moreover, both anxiety and distressful thoughts can occupy cognitive resources (working memory and attentional focus control) available for processing information and handling complex tasks, especially in performance situations, and interfere with the transfer and inhibition functions of the central executive system, which has a greater negative impact on processing efficiency than on operational performance [25]. Thus, reducing anxiety and painful thoughts can allow more attentional focus and working memory to be allocated to tasks directly related to academic performance, thereby improving AP.

\subsection{Information Storage-Memory}

Lykins et al. (2012) researched that those 33 adults practising MM for a long time (an average of 6 years) were compared to a group of non-meditators with controlled demographics [26]. The results showed that the sole improvement was in short-term memory's free recall and clue recall [26]. MM practice has been shown to enhance WM [11] and working memory capacity (WMC)[15]. WM can be promoted by improving attention, particularly information quality and subsequent decision-making processes during MM practice [11]. As for the neuropsychological explanation of why mindfulness meditation improves WM and WMC, it is proved that mindfulness training can increase the hippocampus, which is an associated brain region with WM [27]. Furthermore, since anxiety can hinder the central executive processes [25] and MM was shown to relieve anxiety [28], this could be a mechanism through which MM can improve STM.

The impact of WM on AP is reflected in the improvement of specific disciplines or learning abilities. It is proved that WM is significantly related to attainment in mathematics [29]. According to Raghubar (2010), WM training has been found to be positively associated with mathematics ability, particularly in children and children with math difficulties, whereas this relationship is affected by factors such as age, skill level, and how mathematical problems are presented [29]. The visualspatial WM is crucial for increasing mathematics performance [30,31]. Kyttaelae and Lehto (2008) suggested that the effect of visuospatial WM on mathematical performance is mediated by fluid intelligence, which is dependent on visuospatial WM [31]. Moreover, it is proved that WM can improve the reading comprehension ability of children [30]. Auditory-verbal WM plays an essential role in improving reading comprehension [30]. Furthermore, it is proved that WM deficits are related to some developmental learning disorders, including attention-deficit hyperactivity disorder (ADHD), dyslexia, and specific language impairment [32]. Friedman (2017) suggests that there is a connection between working memory impairments and reading problems in children with ADHD [33]. Therefore, training on improving WM can help reduce the symptoms of ADHD and improve their AP.

\subsection{Executive Cognition (Executive Function)}

What the nature of EF structure is has been debated, but the generally accepted theoretical framework has inhibition, working memory updating, and transfer as essential components that are interconnected, and some complex EF tasks may require some combination and coordination of these EF components [34].

Previous studies confirmed that there were significant positive effects of MM on EF and that meditation could be beneficial for EF in either the long or short term [12, 35, 36]. Helber (2012) argued that MM could improve executive function, but it remained questionable whether there was a significant effect on all executive functions questionable [36]. Gallant (2016) investigated the specific benefits of MM on each subfunction of EF based on Miyake et al.'s (2000) hierarchical EF model; however, the nature of these effects was complex, and the inferences were only partially confirmed [20,35]. More critical to the question of the effect of MM on AP is whether MM has an effect on EF and how it has a final effect on AP through EF. As can be seen from previous studies, although it remained uncertain whether there was a significant effect on all sub-functions of EF, and some studies had opposite results (e.g., inhibition). However, there is no doubt that MM can have a beneficial effect on EF.

EF is an essential skill for success in school life, cognitive, social, and psychological development [37], especially for AP, and it can even be argued that EF plays a central role in maintaining and calibrating the development of academic skills and overall AP [38]. A large body of research demonstrated that EF was significantly and positively correlated with academic achievement, particularly in the areas of mathematics and reading, and that EF was trainable. However, there was also some uncertainty, for example, whether EF is domain-general or domain-specific [34]. There is also some uncertainty about the magnitude of the effect of EF on academic achievement in relation to the educational stage. There is evidence that EF was more strongly related to AP and academic achievement at early educational stages [39], but it has also been argued that because EF was not only trainable and could be improved at any age through many different methods [37]. Taken together, the above research and theoretical evidence suggested that MM training could lead to significant 
improvements in EF as a whole, thereby increasing students' AP and academic achievement.

\section{CONCLUSION}

In conclusion, student's AP could be improved by $\mathrm{MM}$ in three ways (attention, memory, and executive function) by applying three components of the information processing theory, including cognitive process (mindfulness meditation can improve students' academic performance by improving attention on learning), information storage (by improving their working memory), and executive cognition (by improving their overall executive function).

This study summarized the internal mechanism of MM's influences on students' AP by applying the IPT, thereby providing a new research system for follow-up related researchers. Moreover, the study allowed students to understand better the internal mechanism of MM and AP, thereby increasing their participation in $\mathrm{MM}$ invention and academic outcomes. Furthermore, the importance of MM in schools and society might increase. Therefore, more MM activities might be carried out, and more MM-related applications might be developed to improve students' AP.

The existing literature still has some limitations to be addressed. In the case of MM, the current literature lacks a careful consideration of various practice methods and techniques in terms of dimensions such as frequency, depth, and intensity. The location, frequency, duration, training style and medium of $\mathrm{MM}$ practice and interaction with individual differences (e.g., openness to experience, gender) may influence the effectiveness of MM [4]. There may be different experiences and effects between following MM instruction on an app and offline teacher instruction, as well as between groups and individuals. For example, the presence of other practitioners in a group exercise may reduce the effectiveness of MM, reflection, and relaxation [40]. Regarding the subjects (i.e., students), the validity and generalizability of the findings still need to be investigated because of the small number of participants in the trials in the existing experiments. Many studies have not considered the confounding effects of demographic variables (e.g., gender, age, socioeconomic status, religion) on the relationship between MM and AP. For example, individuals with higher socioeconomic status have access to more resources to achieve academic success. Thus, the lack of control for certain variables also reduces the generalizability of the results.

There has been much discussion in the previous literature about whether MM can improve students' AP [4]. In future work, researchers can explore more and analyze how MM can be used more effectively in education, such as when to meditate, how long to meditate, and how the most beneficial and efficient is for students.

\section{REFERENCES}

[1] O. Vorontsova-Wenger, P. Ghisletta, V. Ababkov, K. Barisnikov, Relationship between mindfulness, psychopathological symptoms, and academic performance in university students, Psychological reports, 124(2), 2021, pp. 459-478. DOI: https://doi.org/10.1177/0033294119899906

[2] S. Shapiro, K. Brown, J. Astin, Toward the integration of meditation into higher education: A review of research evidence, Teachers College Record, 113(3), 2011, pp. 493-528.

[3] W. Van Gordon, E. Shonin, A. Sumich, E.C. Sundin, MD. Griffiths, Meditation awareness training (MAT) for psychological well-being in a subclinical sample of university students: a controlled pilot study, Mindfulness, 5(4), 2014, pp. 381-391. DOI: https://doi.org/10.1007/s12671-012-0191-5

[4] M. Baranski, C.A. Was, Can mindfulness meditation improve short-term and long-term academic achievement in a higher-education course? College Teaching, (6), 2019, pp. 1-8. DOI: https://doi.org/10.1080/87567555.2019.1594150

[5] DD. Biber, Integration of a mindfulness meditation lab for university students, Building Healthy Academic Communities Journal, 4(2), 2020, pp. 8895. DOI: https://doi.org/10.18061/bhac.v4i2.7666

[6] J. Kabat-Zinn, Full catastrophe living: how to cope with stress, pain and illness using mindfulness meditation ([New edition], reprinted. ed.). London: Piatkus, 2007.

[7] L. Hilton, S. Hempel, B.A. Ewing, E. Apaydin, L. Xenakis, S. Newberry, B. Colaiaco, A.R. Maher, R.M. Shanman, M.E. Sorbero, M.A. Maglione, mindfulness meditation for chronic pain: systematic review and meta-analysis, Annals of Behavioral Medicine, 2017, DOI: https://doi.org/10.1007/s12160-016-9844-2

[8] J. Kabat-Zinn, An outpatient program in behavioral medicine for chronic pain patients based on the practice of mindfulness meditation: Theoretical considerations and preliminary results, General Hospital Psychiatry, 4(1), 1982, pp. 33-47. DOI: https://doi.org/10.1016/0163-8343(82)90026-3

[9] Z.V. Segal, J.M.G.Williams, J.D. Teasdale, Mindfulness-based cognitive therapy for depression: A new approach to preventing relapse, New York, NY: Guilford Press, 2002. 
[10] S. J. Bóo, J. Childs-Fegred, S. Cooney, B. Datta, G. Dufour, P.B. Jones, \& J.A. Galante, follow-up study to a randomised control trial to investigate the perceived impact of mindfulness on academic performance in university students, Counselling and Psychotherapy Research, 20(2), 2020, pp. 286-301. DOI: https://doi.org/10.1002/capr.12282

[11] M. Van Vugt, A. Jha, Investigating the impact of mindfulness meditation training on working memory: A mathematical modeling approach, Cognitive, Affective, \& Behavioral Neuroscience, 11(3), 2011, pp. 344-353. DOI: https://doi.org/10.3758/s13415-011-0048-8

[12] F. Zeidan, D.R. Vago, Mindfulness meditationbased pain relief: a mechanistic account, Annals of the New York Academy Sciences, 2016, 1373(1), pp. 114-27.

DOI: https://doi.org/10.1111/nyas.13153.

[13] C.P. Campbell, Impact of a mindfulness-based intervention on students in grades 3-5, Theses and Dissertations, 216, 2021. DOI: https://scholar.stjohns.edu/theses_dissertations/216

[14] C. Franco, I. Mañas, A.J. Cangas, J. Gallego, The applications of mindfulness with students of secondary school: Results on the academic performance, self-concept and anxiety, In Knowledge Management, Information Systems, ELearning, and Sustainability Research, Vol. 111, Springer Berlin Heidelberg, 2010, pp. 83-97. DOI: https://doi.org/10.1007/978-3-642-16318-0_10

[15] MD. Mrazek, M.S. Franklin, D.T. Phillips, B. Baird, J.W. Schooler, Mindfulness training improves working memory capacity and GRE performance while reducing mind wandering, Psychological Science, 24(5), 2013, pp. 776-781. DOI: https://doi.org/10.1177/0956797612459659

[16] N. Çeliköz, Y. Erisen, M. Sahin, Cognitive learning theories with emphasis on latent learning, gestalt and information processing theories, Journal of Educational and Instructional Studies in the World, Online Submission, 9(3), 2019, pp.18-33. https://search.ebscohost.com/login.aspx?direct=tru $\mathrm{e} \& \mathrm{db}=\mathrm{eric} \& \mathrm{AN}=\mathrm{ED} 598366 \&$ lang=zhcn\&site=eds-live.

[17] J.R. Slate, J.R. Charlesworth, Information processing theory: Classroom applications, Reading Improvement, 26(1), 1988, pp. 2-6. https://eric.ed.gov/?id=ED293792

[18] A.G. Kandarakis, M.S. Poulos, Teaching implications of information processing theory and evaluation approach of learning strategies using LVQ neural network, WSEAS Transactions on
Advances in Engineering Education, 5, 2008, pp. 111-119. http://www.wseas.us/elibrary/transactions/education/2008/educationex.pdf

[19] D.H. Schunk, Learning theories: An educational perspective (7th ed.), Boston, MA: Pearson, 2016.

[20] A. Miyake, N.P. Friedman, M.J. Emerson, et al., The unity and diversity of executive functions and their contributions to complex 'Frontal Lobe'tasks: a latent variable analysis, Cognitive Psychology, 41(1), 2000, pp. 49-100. DOI: https://doi.org/10.1006/cogp.1999.0734

[21] D.S. Black, R.J. Semple, P. Pokhrel, et al., Component processes of executive functionmindfulness, self-control, and working memoryand their relationships with mental and behavioral health, Mindfulness, 2, 2011, pp. 179-185. DOI: https://doi.org/10.1007/s12671-011-0057-2

[22] U.S. Spitzer, W. Hollmann, Experimental observations of the effects of physical exercise on attention, academic and prosocial performance in school settings, Trends in neuroscience and education, 2(1), 2013, pp. 1-6. DOI : https://doi.org/10.1016/j.tine.2013.03.002

[23] S. Cid-Sillero, E. Pascual-Sagastizabal, J.I. Martínez-de-Morentin, Influence of self-esteem and attention on the academic performance of ESO and FPB students, Revista de Psicodidáctica (English Ed.), 25(1), 2020, pp. 59-67. DOI: https://doi.org/10.1016/j.psicod.2019.06.001

[24] J. Beauchemin, T.L. Hutchins, F. Patterson, Mindfulness meditation may lessen anxiety, promote social skills, and improve academic performance among adolescents with Learning disabilities, Complementary Health Practice Review, 13(1), 2008, pp. 34-45. DOI: https://doi.org/10.1177/1533210107311624

[25] N. Derakshan, M. W. Eysenck, Anxiety, processing efficiency, and cognitive performance: New developments from attentional control theory, European Psychologist, 14(2), 2009, pp.168-176. DOI: https://doi.org/10.1027/1016-9040.14.2.168

[26] E.L.B. Lykins, R.A. Baer, L.R. Gottlob, Performance-based tests of attention and memory in long-term mindfulness meditators and demographically matched nonmeditators, Cognitive Therapy and Research, 36(1), 2012, pp. 103-114. DOI: https://doi.org/10.1007/s10608-010-9318-y

[27] E. Luders, F. Kurth, A.W. Toga, K.L. Narr, C. Gaser, Meditation effects within the hippocampal complex revealed by voxel-based morphometry and 
cytoarchitectonic probabilistic mapping, Frontiers in Psychology, 4, 2013, pp. 398-398. DOI: https://doi.org/10.3389/fpsyg.2013.00398

[28] S.G. Hofmann, A.T. Sawyer, A.A. Witt, D. Oh, The effect of mindfulness-based therapy on anxiety and depression, Journal of Consulting and Clinical Psychology, 78(2), 2010, pp. 169-183. DOI: https://doi.org/10.1037/a0018555

[29] K.P. Raghubar, M.A. Barnes, S.A. Hecht, Working memory and mathematics: A review of developmental, individual difference, and cognitive approaches. Learning and Individual Differences, 20(2), 2010, pp. 110-122. DOI: https://doi.org/10.1016/j.lindif.2009.10.005

[30] M. Rogers, H. Hwang, M. Toplak, M. Weiss, R. Tannock, Inattention, working memory, and academic achievement in adolescents referred for attention deficit/hyperactivity disorder (ADHD), Child Neuropsychology, 17(5), 2011, pp. 444-458. DOI:

https://doi.org/10.1080/09297049.2010.544648

[31] M. Kyttaelae, J.E. Lehto, Some factors underlying mathematical performance: The role of visuospatial working memory and non-verbal intelligence, European Journal of Psychology of Education, 23(1), 2008, pp. 77-94. DOI: https://doi.org/10.1007/BF03173141

[32] J. Holmes, S.E. Gathercole, D.L. Dunning, Poor working memory. Impact and interventions. Advances in Child Development and Behavior, 39(C), 2010, pp. 1-43. DOI: https://doi.org/10.1016/B978-0-12-374748$8.00001-9$

[33] L.M. Friedman, MD. Rapport, J.S. Raiker, S.A. Orban, S.J. Eckrich, Reading comprehension in boys with ADHD: The mediating roles of working memory and orthographic conversion, Journal of Abnormal Child Psychology, 45(2), 2017, pp.273287. DOI: https://doi.org/10.1007/s10802-0160171-7

[34] J.R. Best, P.H. Miller, J.A. Naglieri, Relations between executive function and academic achievement from ages 5 to 17 in a large, representative national sample, Learning and Individual Differences, 22(4), 2011, pp. 327336, DOI: https://doi.org/10.1016/j.lindif.2011.01.007.

[35] S.N. Gallant, Mindfulness meditation practice and executive functioning: Breaking down the benefit,Consciousness and Cognition, 40, 2016, pp. 116-130.

DOI: https://doi.org/10.1016/j.concog.2016.01.005
[36] C. Helber, N.A. Zook, M. Immergut, Meditation in Higher Education: Does it Enhance Cognition?, Innovative High Education, 37(5), 2012, pp. 349-358. DOI: https://doi.org/10.1007/s10755-012-9217-0

[37] A. Diamond, Executive functions, Annu Rev Psychol, 64, 2013, pp. 135-68. DOI: https://doi.org/10.1146/annurev-psych-113011143750

[38] L. Visu-Petra, L. Cheie, O. Benga, M. Miclea, Cognitive control goes to school: The impact of executive functions on academic performance, Procedia - Social and Behavioral Sciences, 11, 2011, pp. 240-244. DOI: https://doi.org/10.1016/j.sbspro.2011.01.069.

[39] L. Altemeier, J. Jones, R.D. Abbott, V.W. Berninger, Executive functions in becoming writing readers and reading writers: Note taking and report writing in third and fifth graders, Developmental Neuropsychology, 29, 2006, pp. 161-73. DOI: http://dx.doi.org/10.1207/s15326942dn2901_8

[40] E.L. Solar, The effects of mindfulness meditation on adolescents with high-incidence disabilities, George Mason University. ProQuest Dissertations Publishing, 2013, 3606502. 